\title{
Consumption Externality and Indeterminacy under Increasing Returns to Scale and Endogenous Capital Depreciation*
}

\author{
Gaowang Wang ${ }^{\dagger}$ \\ Central University of Finance and Economics \\ Heng-fu Zou \\ Central University of Finance and Economics
}

December 7, 2013

\begin{abstract}
This paper incorporates negative consumption externality embodying "jealousy" and "running away from the Joneses" into Guo and Lansing (2007)'s model with production externality and endogenous depreciation, and examines how consumption externality helps to generate equilibrium indeterminacy together with production externality. Specifically, the existence of consumption externality reduces the upper and lower bounds of production externality for local indeterminacy, and when the degree of consumption externality increases, the upper and lower bounds of production externalities for local indeterminacy are both reduced.

Keywords: Consumption Externality, Production Externality, Indeterminacy, Endogenous Depreciation

JEL Classification Numbers: C62, E21, E22.
\end{abstract}

${ }^{*}$ We thank Feng Shi for his excellent research assistance. Wang thanks China Postdoctoral Foundation (project number: 2013T60249) for financial support. All errors are the responsibility of the authors.

${ }^{\dagger}$ School of Economics, Central University of Finance and Economics, Beijing, 100081, China. E-mail: wanggaowang@gmail. com.

${ }^{\ddagger}$ China Economics and Management Acedamy, Central University of Finance and Economics, Beijing, 100081, China. E-mail: hzoucema@gmail.com. 


\section{Introduction}

Considerable progress has been made over the past two decades in understanding the conditions needed to generate equilibrium indeterminacy in real business cycle models with production externalities or monopolistic competition. In the original one-sector models of Benhabib and Farmer (1994) and Farmer and Guo (1994), Local indeterminacy requires an implausible high degree of increasing returns-to-scale or externality in production. Subsequent research has shown that RBC models with multiple sectors of production (Benhabib and Farmer, 1996; Perli, 1998; Weder, 2000; Harrison, 2001) or endogenous capital depreciation (Wen, 1998; Guo and Lansing, 2007) can generate local indeterminacy with much lower degrees of increasing returns. Moreover, a combination model that incorporates both multiple production sectors and endogenous capital utilization may give rise to equilibrium indeterminacy only within an extremely narrow range of increasing returns (Guo and Harrison, 2001).

Another research line relates equilibrium indeterminacy to consumption externality. It has been shown that consumption externalities do not generate indeterminacy of the equilibrium path (1) when the labor supply is exogenous (Liu and Turnovsky, 2005); or (2) when the utility function has the restricted homotheticity $(\mathrm{RH})$ property $^{1}$ (Guo, 1999; Weder, 2000) even if the labor supply is endogenous. However, indeterminacy can arise when consumption externalities modify the Frisch labor supply, which requires that the utility function is nonseparable between consumption and leisure (Alonso-Carrera, Caballe, and Raurich, 2008). However, there is no work on the interactions between consumption externality and production externality in determining equilibrium indeterminacy in the literature.

This paper develops a straighforward extension of the one-sector, increasing returns-to-scale, and endogenous capital depreciation model of Guo and Lansing (2007) by incorporating negative consumption externality in the sense of Dupor and Liu (2003) and Liu and Turnovsky (2005). The RH property exhibited by the utility function in Guo and Lansing (2007) due to the separability between consumption and leisure tells that consumption externality cannot generate indeterminacy alone without the existence of production externality. However, the paper shows that due to the existence of consumption externality, compared to Guo and Lansing (2007), the requirement for production externality to generate equilibrium indeterminacy can be further reduced.

In our model, households have separable utility on consumption and leisure. And the utility on consumption depends not only on private consumption but also on the average consumption

\footnotetext{
${ }^{1}$ The utility function satisfies the restricted homotheticity property when the MRS between an agent's consumption and consumption spillovers is constant along the equilibrium path.
} 
of the society. For our purpose, the dependence of an individual's utility on the average consumption, captures negative consumption externalities that reduce the felicity that each individual obtains from his or her own consumption and decrease the marginal rate of substitution between an agent's own consumption and leisure. That is, the individuals exhibit "jealousy" and "running away from the Joneses". Similar to Guo and Lansing (2007), firms make decisions about the amount of labor devoted to production, the level of expenditures devoted to investment and maintenance, and the utilization rate of the existing capital. The production technology employed by firms is subject to an external effect that depends on the economy-wide average levels of utilized capital and labor inputs. By utilizing the standard procedure of log-linearizing the equilibrium conditions around the steady state, we construct a two-dimension linearized system that depicts the stability properties of the steady state as a function of the externality parameters. It is shown that the existence of consumption externality reduces the upper and lower bounds of production externality for local indeterminacy; and when the degree of consumption externality increases, the upper and lower bounds of production externalities for local indeterminacy are both decreased. The intuition for why consumption externality can make equilibrium indeterminacy easier to obtain is that more effective adjustments of private consumption due to consumption externality promote agents' optimistic expectations as a self-fulfilling equilibrium driven by production externalities.

The rest of this paper is organized as follows. Section 2 describes the model set-up including both consumption externality in households' behaviors and production externality in firms' behaviors. Section 3 solves competitive equilibirum and the two-dimension dynamic system. Section 4 discusses the relationship between externalities and local indeterminacy. And the concluding remarks are summerized in section 5.

\section{The Model}

We introduce consumption externality into Guo and Lansing (2007)'s local indeterminacy RBC model with production externality and maintenance expenditures. In the decentralized economy, a representative household supplies labor by taking the real wage as given, and its utility function is separable between consumption and leisure and displays negative consumption externality exhibiting "jealousy" and "running away from the Joneses". The household is the owner of a representative firm that makes decisions about production, investment, maintenance and capital utilization, and the firm's production technology displays increasing return to scale due to positive production externality. 


\subsection{Households}

The economy is populated by a large number of identical, infinitely-lived households, each endowed with one unit of time, who choose sequences of consumption $c_{t}$ and total hours worked $n_{t}$ to maximize:

$$
E_{0} \sum_{t=0}^{\infty} \beta^{t} u\left(c_{t}, \bar{c}_{t}, n_{t}\right)
$$

subject to the budget constraint

$$
c_{t}=w_{t} n_{t}+\pi_{t}
$$

where $\beta \in(0,1)$ is the discount factor, $w_{t}$ is the real wage, and $\pi_{t}$ represents profits paid out by the firm in the form of dividends. It is assumed that the utility function of a representative household depends not only on his own consumption $c$ and labor (leisure) $n$ separably, but also on the average per capita consumption level, $\bar{c}$, namely, $u\left(c_{t}, \bar{c}_{t}, n_{t}\right)=\frac{\left(c_{t} \bar{c}_{t}^{\epsilon}\right)^{1-\sigma}-1}{1-\sigma}-\frac{A n_{t}^{1+\gamma}}{1+\gamma}$, where $A>0, \sigma \in[0,1)$, and $\gamma \geq 0$, are the inverses of the elasticity of intertemporal substitution in consumption and labor supply, respectively, and $\epsilon<0$. The specification of preference implies (1) "jealousy" (i.e., $u_{\bar{c}}=\epsilon\left(c_{t} \bar{c}_{t}^{\epsilon}\right)^{1-\sigma} \bar{c}_{t}^{-1}<0$ ), and (2) "running away from the Joneses" (i.e., $\left.d\left(\frac{u_{n}}{u_{c}}\right) / d \bar{c}=A \epsilon(1-\sigma) n_{t}^{\gamma} c_{t}^{\sigma} \bar{c}_{t}^{-\epsilon(1-\sigma)-1}<0\right)$, which together exhibit negative consumption externality extensively examined by Dupor and Liu (2003) and Liu and Turnovsky (2005).

The first-order condition for the household's optimization problem is given by

$$
A c_{t} n_{t}^{\gamma}=w_{t}\left(c_{t} \bar{c}_{t}^{\epsilon}\right)^{1-\sigma}
$$

which equates the household's marginal rate of substitution between consumption and leisure to the real wage.

\section{$2.2 \quad$ Firms}

The firms' behaviors are very similar to Guo and Lansing (2007). It is assumed that the labor market is perfectly competitive and a large number of identical competitive firms acting in the best interests of the household-owners maximize a discounted stream of profits. By taking $\left\{w_{t}\right\}$ as given and choosing the sequences of $\left\{n_{t}, u_{t}, m_{t}, k_{t+1}\right\}$, the firm maximizes the following discounted stream of expected profits:

$$
\max _{\left\{n_{t}, u_{t}, m_{t}, k_{t+1}\right\}} E_{0}\{\sum_{t=0}^{\infty} \beta^{t}\left[\left(c_{t} \bar{c}_{t}^{\epsilon}\right)^{-\sigma} \bar{c}_{t}^{\epsilon}\right] \underbrace{\left(y_{t}-w_{t} n_{t}-i_{t}-m_{t}\right)}_{\pi_{t}}\},
$$


subject to the firm's production function

$$
y_{t}=\bar{e}_{t}\left(u_{t} k_{t}\right)^{\alpha} n_{t}^{1-\alpha}, 0<\alpha<1 .
$$

its capital accumulation equation

$$
k_{t+1}=\left(1-\delta_{t}\right) k_{t}+i_{t}, k_{0} \text { is given. }
$$

The symbol $\bar{e}_{t}$ represents a productive externality that takes the form

$$
\bar{e}_{t}=\left(\bar{u}_{t} \bar{k}_{t}\right)^{\alpha \eta} \bar{n}_{t}^{(1-\alpha) \eta}, \eta \geq 0
$$

where $\left(\bar{u}_{t} \bar{k}_{t}\right)$ and $\left(\bar{n}_{t}\right)$ are the economy-wide averages levels of utilized capital and production labor inputs; the rate of endogenous capital depreciation $\delta_{t} \in(0,1)$ is postulated to follow the following rule of evolutions

$$
\delta_{t}=\tau \frac{u_{t}^{\theta}}{\left(m_{t} / k_{t}\right)^{\phi}}, \tau>0, \theta>1, \text { and } \phi \geq 0,
$$

where $u_{t}$ is the endogenous rate of capital utilization, $m_{t}$ represents goods expenditures on maintenance, $m_{t} / k_{t}$ is the "maintenance cost rate" (Licandro and Puch (2000)), $\theta$ and $\phi$ are the elasticities of the depreciation rate with respect to the capital utilization rate and the maintenance cost rate, respectively. Equations (7) implies that an increase in the capital utilization rate $u_{t}$ serves to accelerate the depreciation rate. However, an increase in maintenance serves to slow the depreciation rate. Firms act in the best interests of households such that realized profits in period $t$ are valued using the household's marginal utility of consumption, given by $\frac{\partial u_{t}}{\partial c_{t}}=\left(c_{t} \bar{c}_{t}^{\epsilon}\right)^{-\sigma} \bar{c}_{t}^{\epsilon}$.

The firm's first-order conditions with respect to the indicated variables are

$$
\begin{gathered}
n_{t}:(1-\alpha) \frac{y_{t}}{n_{t}}=w_{t} \\
u_{t}: \frac{\alpha}{\theta} \frac{y_{t}}{k_{t}}=\delta_{t} \\
m_{t}: 1=\phi \frac{\delta_{t} k_{t}}{m_{t}} \\
k_{t+1}:\left(c_{t} \bar{c}_{t}^{\epsilon}\right)^{-\sigma} \bar{c}_{t}^{\epsilon}=\beta E_{t}\left\{\left(c_{t+1} \bar{c}_{t+1}^{\epsilon}\right)^{-\sigma} \bar{c}_{t+1}^{\epsilon}\left[\alpha \frac{y_{t+1}}{k_{t+1}}+1-(1+\phi) \delta_{t+1}\right]\right\}
\end{gathered}
$$


together with the transversality condition $\lim _{t \rightarrow \infty} \beta^{t}\left(k_{t+1}\left(c_{t} \bar{c}_{t}^{\epsilon}\right)^{-\sigma} \bar{c}_{t}^{\epsilon}\right)=0$. Equation (8) tells that the firm hires labor to the point where the marginal product of labor is equal to the real wage. Equation (9) shows that the firm utilizes capital to the point where the marginal benefit of more output is equal to the marginal cost of faster depreciation. Equation (10) shows that the firm undertakes repairs and maintenances on the physical capital to the point where the marginal expenditure on these activities equals the marginal reduction in the firm's depreciation expense. Equation (11) is the standard intertemporal consumption Euler equation which is modified to reflect how the negative consumption externality related to the average level of consumption affects the mariginal utility of private consumption.

Combining equations (9) and (10) gives us $m_{t}=(\phi \alpha / \theta) y_{t}$, which shows that the firm allocates a constant fraction of total resources to repairs and maintenances in optimum. This also implies that the expenditures on repairs and maintenances are procyclical and perfectly correlated with output, which is consistent with the empirical evidence documented by McGrattan and Schmitz (1999). Substituting the above equation and (9) into (7), we solve $u_{t}$ as a function of $y_{t}$ and $k_{t}$

$$
u_{t}=\left[\frac{\phi^{\phi}}{\tau}\left(\frac{\alpha}{\theta}\right)^{1+\phi}\right]^{\frac{1}{\theta}} y_{t}^{\frac{1+\phi}{\theta}} k_{t}^{-\frac{1+\phi}{\theta}}
$$

\section{Competitive Equilibrium and Dynamic System}

In competitive equilibrium of the economy, all consumers and firms take the same actions such that $c_{t}=\bar{c}_{t}, n_{t}=\bar{n}_{t}, u_{t}=\bar{u}_{t}$, and $k_{t}=\bar{k}_{t}$ for all $t$. We substitute equation (6) into equation (4) and obtain the aggregate production technology which displays increasing returns to scale:

$$
y_{t}=\left[\left(u_{t} k_{t}\right)^{\alpha} n_{t}^{1-\alpha}\right]^{1+\eta},
$$

where $(1+\eta)$ stands for the degree of increasing returns. Furthermore, utilizing equations (7) and (9) to solve for $u_{t}$ and substituting the resulting expressions into (13) lead to the reducedform social technology as a function of $k_{t}$ and $n_{t}$ as follows:

$$
y_{t}=B k_{t}^{\alpha_{k}} n_{t}^{\alpha_{n}}
$$

where

$$
B=\left[\frac{\phi^{\phi}}{\tau}\left(\frac{\alpha}{\theta}\right)^{1+\phi}\right]^{\frac{\alpha(1+\eta)}{\theta-\alpha(1+\eta)(1+\phi)}},
$$




$$
\begin{aligned}
& \alpha_{k}=\frac{\alpha(1+\eta)(\theta-1-\phi)}{\theta-\alpha(1+\eta)(1+\phi)}, \\
& \alpha_{n}=\frac{(1-\alpha)(1+\eta) \theta}{\theta-\alpha(1+\eta)(1+\phi)} .
\end{aligned}
$$

Similar to Guo and Lansing (2007), we consider the case satisfying $\alpha_{n}>0$ (i.e., a positve output elasticity of labor), $\alpha_{k}>0$ (i.e., a positive output elasticity of capital), and $\alpha_{k}<1$ (i.e., ruling out sustained endogenous growth), which tells that:

$$
\theta-\alpha(1+\eta)(1+\phi)>0, \theta-1-\phi>0, \alpha(1+\eta)<1 .
$$

The optimality conditions of (3) and (11) are also changed into

$$
\begin{gathered}
A n_{t}^{\gamma}=w_{t} c_{t}^{\alpha_{c}}, \\
c_{t}^{\alpha_{c}}=\beta E_{t}\left\{c_{t+1}^{\alpha_{c}}\left[\alpha \frac{y_{t+1}}{k_{t+1}}+1-(1+\phi) \delta_{t+1}\right]\right\},
\end{gathered}
$$

where $\alpha_{c} \equiv-\sigma(1+\epsilon)+\epsilon$.

A symmetric equilibrium of the economy $\left(w_{t}, c_{t}, n_{t}, u_{t}, m_{t}, y_{t}, \delta_{t}, c_{t+1}, k_{t+1}\right)$ is completely determined by the dynamic system composed of the following nine equations: (2), (5), (7), (8), (9), (10), (14), (16), and (17). In particular, combining Eqs. (8), (14), and (16) gives rise to an expression of $n_{t}$ as a function of $k_{t}$ and $c_{t}$

$$
n_{t}=\left[\frac{(1-\alpha) B}{A}\right]^{\frac{1}{1+\gamma-\alpha_{n}}} k_{t}^{\frac{\alpha_{k}}{1+\gamma-\alpha_{n}}} c_{t}^{\frac{\alpha_{c}}{1+\gamma-\alpha_{n}}} .
$$

The stationary equilibrium of the economy $(c, n, u, m, k, \delta, y, w)$ is determined uniquely by the following equations: $\delta=\frac{1-\beta}{\beta} \frac{1}{(\theta-1-\phi)}, u=\left[\frac{\phi^{\phi}}{\tau}\left(\frac{\alpha}{\theta}\right)^{1+\phi}\right]^{\frac{1}{\theta}}\left(\frac{\theta}{\alpha}\right)^{\frac{1+\phi}{\theta}} \delta^{-\frac{1+\phi}{\theta}}, \frac{y}{k}=\frac{\theta}{\alpha} \delta, \frac{m}{k}=\phi \delta, \frac{c}{k}=$ $\frac{[\theta-\alpha(1+\phi)]}{\alpha} \delta, n=\left[\frac{(1-\alpha) B}{A}\right]^{\frac{1}{1+\gamma-\alpha_{n}}} k^{\frac{\alpha_{k}}{1+\gamma-\alpha_{n}}} c^{\frac{\alpha_{c}}{1+\gamma-\alpha_{n}}}, A n^{\gamma}=w c^{\alpha_{c}}$, and $w=(1-\alpha) \frac{y}{n}$. Equipped with the definition $\widetilde{x}_{t} \equiv \log \left(\frac{x_{t}}{x}\right)$ (i.e., $x_{t} \equiv x e^{\widetilde{x}_{t}}$ ), we $\log$-linearize the above nine equations around the steady state, combine them by suitable substitutions, and eventually can obtain the following log-linearized system about $\left(\widetilde{k}_{t}, \widetilde{c}_{t}\right)$ as follows:

$$
\left(\begin{array}{c}
\widetilde{k}_{t+1} \\
\widetilde{c}_{t+1}
\end{array}\right)=\underbrace{\left(\begin{array}{cc}
\lambda_{1} & \lambda_{2} \\
\frac{\lambda_{1} \lambda_{3}}{\lambda_{4}} & \frac{\sigma(1+\epsilon)-\epsilon+\lambda_{2} \lambda_{3}}{\lambda_{4}}
\end{array}\right)}_{J}\left(\begin{array}{c}
\widetilde{k}_{t} \\
\widetilde{c}_{t}
\end{array}\right),
$$


where $J$ is the Jacobian matrix of partial derivatives of the transformed dynamical system. The elements that make up the Jacobian matrix are given by ${ }^{2}$

$$
\begin{aligned}
& \lambda_{1}=1-\frac{\alpha_{k} \delta(1+r)[\theta-\alpha(1+\phi)]}{\alpha\left(\alpha_{n}-1-r\right)}, \\
& \lambda_{2}=\frac{\delta[\theta-\alpha(1+\phi)]\left[1+r-\alpha_{n}\left(1+\alpha_{c}\right)\right]}{\alpha\left(\alpha_{n}-1-r\right)}, \\
& \lambda_{3}=\frac{(1-\beta)\left[\left(1-\alpha_{k}\right)(1+r)-\alpha_{n}\right]}{\alpha_{n}-1-r}, \\
& \lambda_{4}=\sigma(1+\epsilon)-\epsilon+\frac{\alpha_{n} \alpha_{c}(1-\beta)}{\alpha \alpha_{n}-1-r},
\end{aligned}
$$

where $\rho \equiv 1 / \beta-1$ is the household's time prefence rate, and $\delta \equiv \rho /(\theta-1-\phi)$ is the steady-state depreciation rate. Then, the expressions for the determinant and trace of $\mathrm{J}$ are

$$
\begin{aligned}
\operatorname{det}(J) & =\frac{\lambda_{1}[\sigma(1+\epsilon)-\epsilon]}{\lambda_{4}}, \\
\operatorname{tr}(J) & =\lambda_{1}+\frac{\sigma(1+\epsilon)-\epsilon+\lambda_{2} \lambda_{3}}{\lambda_{4}} .
\end{aligned}
$$

\section{Externalities and Local Indeterminacy}

The local stability properties of the steady state are determined by comparing the number of eigenvalues of $J$ located inside the unit circle (i.e., the moduli of the eigenvalues are less than one) with the number of initial conditions. There is one initial condition represented by $k_{0}$ in the model. For the two-dimension log-linearized system given by (19), the steady state is indeterminate (i.e., a real or spiral sink), if both eigenvalues of $J$ lie inside the unit circle. This will occur if and only if

$$
\begin{gathered}
-1<\operatorname{det}(J)<1, \\
-[1+\operatorname{det}(J)]<\operatorname{tr}(J)<1+\operatorname{det}(J) .
\end{gathered}
$$

In the following discussions, we will examine these necessary and sufficient conditions and quantitatively investigate the local stability properties using the standard parameter values. Following Wen (1998) and Guo and Lansing (2007), we choose $\gamma=0$ to reflect the commonlyused specification of Hansen's "indivible labor" in the RBC literature.

\footnotetext{
${ }^{2}$ Notice that the elements of $\mathrm{J}$ do not depend on either the labor disutility parameter $A$ or the constant $\tau$ in the depreciation technology (7).
} 
Proposition 1: $\operatorname{det}(J)<1$ if and only if $-\alpha_{c} \lambda_{1}>\lambda_{4}$ and $\lambda_{4}<0$.

Proof. See the appendix.

Note that the condition $-\alpha_{c} \lambda_{1}>\lambda_{4}$ means that

$$
\frac{\theta}{1+\phi}<\frac{\alpha(1+\gamma)}{(1+\gamma)-\beta(1-\alpha)}
$$

and the condition $\lambda_{4}<0$ implies that

$$
\eta>\frac{\theta[(1+\gamma)-\beta(1-\alpha)]-\alpha(1+\gamma)(1+\phi)}{\beta(1-\alpha) \theta+(1+\gamma) \alpha(1+\phi)} .
$$

It needs to be verified that requirements (15) and (25) on $\eta$ are compatible for certain parameter values of the model. These two requirements together imply:

$$
\beta(1-\alpha) \theta \beta \delta>(1+\gamma)(1-\beta) \alpha
$$

which is analogous to that derived by Wen (1998). For $\beta$ close to one and $\alpha$ small enough, there exist regions of the parameter space such that (26) is satisfied.

If indeterminacy exists in the paremeter regions specified above, similar to Wen (1998) and Guo and Lansing (2007), we can limit our attention to the following simpler one-sided conditions as necessary and sufficient conditions for indeterminacy:

$$
-1<\operatorname{det}(J), \operatorname{tr}(J)<1+\operatorname{det}(J),-[1+\operatorname{det}(J)]<\operatorname{tr}(J) .
$$

The condition $-1<\operatorname{det}(J)$ implies

$$
\eta>\underline{\eta}=\frac{2 \theta}{(1-\alpha) \theta+2 \alpha(1+\phi)-((1-\beta) / \beta)(\theta-\alpha(1+\phi))+(1-\alpha) \theta \beta}-1 .
$$

For those appropriate parameter values, the right-hand side of (28) is larger than the one of (25), which makes (28) more demanding for the size of $\eta$. Since we are usually interested primarily in the smallest value of $\eta$ that gives rise to indeterminacy, we need to care about (28) rather than (25). Using (28), it is easy to know that the following first derivatives hold in the permissible region for $\eta$ :

$$
\frac{d \underline{\eta}}{d \beta}<0, \frac{d \underline{\eta}}{d \alpha}>0, \frac{d \underline{\eta}}{d \theta}>0, \frac{d \underline{\eta}}{d \phi}<0
$$

That is, indeterminacy occurs more easily the less of the time preference rate or the larger of the output elasticity of capital. However, (28) does not depend on the degree of consumption externality $\epsilon$, namely, $\frac{d \underline{\bar{\eta}}}{d \epsilon}=0$. 
The condition $\operatorname{tr}(J)<1+\operatorname{det}(J)$ implies

$$
\eta<\bar{\eta}=\frac{1}{(1-\alpha)(1-\sigma)(1-\epsilon)+\alpha}-1,
$$

the right-hand side of which is less than that of the inequality $\eta<\frac{1}{\alpha}-1$ (i.e., $\alpha(1+\eta)<1$ in equation (27)). This implies that the upper bound of $\eta$ generating indeterminacy is less than that of the models without consumption externalities such as Wen (1998) and Guo and Lansing (2007). Furthermore, we have

$$
\frac{d \bar{\eta}}{d \epsilon}>0, \frac{d \bar{\eta}}{d \sigma}>0, \frac{d \bar{\eta}}{d \alpha}<0
$$

which show that the stronger the consumption externality, the less the upper bound of production externality; and the less the elasticity of intertemporal substitution, the less the upper bound of production externality.

The condition $-[1+\operatorname{det}(J)]<\operatorname{tr}(J)$ implies

$$
\eta>\underline{\underline{\eta}} \equiv \frac{\left\{\delta[\theta-\alpha(1+\phi)(1-\beta)]-4 \alpha \alpha_{c}\right\} \theta}{\alpha_{c}\left\{\begin{array}{c}
{[2 \alpha(1-\beta)-4 \alpha+\delta(\theta-\alpha(1+\phi))(1-\beta)](1-\alpha) \theta} \\
+2 \alpha \delta[\theta-\alpha(1+\phi)](\theta-1-\phi)-4 \alpha^{2}(1+\phi)
\end{array}\right\}+\delta \theta(\theta-\alpha(1+\phi))(1-\beta)}-1 .
$$

The degree of consumption externality $\epsilon$ does enter $\alpha_{c}$ and hence enter $\underline{\underline{\eta}}$. In the benchmark parameter values, we have $\frac{d \underline{\bar{\eta}}}{d \epsilon}=-0.0009$, which tells that in an open neighborhood of the benchmark parameter values, indeterminacy occurs more easily the strong of the degree of consumption externality. However, this effect is very weak quantitatively. Similar to Wen (1998) and Guo ang Lansing (2007), under the most of the realistic parameter values (in particular, $\beta=0.99)$, conditions (28) and (32) are roughly the same.

The necessary and sufficient conditions for indeterminacy are therefore (28), (30), and (32). In order to estimate the regions of indeterminacy in the model and examine how consumption externality helps generate indeterminacy, we generate the regions of indeterminacy in our model (Figure 1) and reproduce the regions of indeterminacy in the Guo and Lansing (2007) model (Figure 2). The benchmark parameter values are as follows:

$$
\alpha=0.3, \beta=0.99, \delta=0.025, \gamma=0, \theta=1.7624, \phi=0.3584, \sigma=0.8 .
$$

The values of $\alpha=0.3, \beta=0.99$, and $\delta=0.025$ are parameterized by Farmer and Guo (1994); $\gamma=0$ is often-used in RBC literature including Wen (1998) and Guo and Lansing (2007); $\theta=1.7624$, and $\phi=0.3584$ are calibrated by Guo and Lansing (2007); $\sigma=0.8$ is calibrated as 
the benchmark case in our model. In Figure 1, we simulate the regions of indeterminacy of our model as functions of $\eta$ when each of these four parameters is allowed to vary while holding the others at their benchmark values. It is seen there that conditions (28), and (32) are virtually the same at $\beta=0.99$, the permissible regions for indeterminacy are very large, and the associated degrees of externality $\eta$ are very low. Compared to Guo and Lansing (2007) in Figure 2, we know that the upper bounds of the degree of production externality for local indeterminacy in our model are obviously less than those in Guo and Lansing (2007)'s model, and in the benchmark case, the upper bound of production externality for local indeterminacy in our model is 1.1368, which less than 2.3333 in Guo and Lansing $(2007)^{3}$; the lower bound of production externality in our model is weakly less than that of Guo and Lansing (2007). However, the distinctions of the two models are very small.

When $\epsilon=0$ as in Guo and Lansing (2007), Figure 3 shows that the model requires $\eta>0.0826$ for local indeterminacy. As the degree of consumption externality increases, the minimum requiremnt of production externality for local indeterminacy decreases qualitatively. However, the changes are very small quantitatively since $\frac{d \underline{\overline{\underline{\eta}}}}{d \epsilon}=-0.0009$ is a very small negative number. The upper bound of the degree of production externality for local indeterminacy decreases when consumption externality becomes stronger. Figure 4 shows that when $\sigma$ is becoming less and less in the region $(0,1)$, the upper bound of the degree of production externality for local indeterminacy decreases more fast, whereas the lower bound changes very slowly.

To gain insight into the mechanism that consumption externality helps to generate local indeterminacy, it is useful to examine the following version of the consumption Euler equation (i.e., (11)) that abstracts from uncertainty:

$$
\left(\frac{c_{t+1}}{c_{t}}\right)^{\sigma}\left(\frac{\bar{c}_{t+1}}{\bar{c}_{t}}\right)^{\epsilon(\sigma-1)}=\beta\left[\alpha \frac{y_{t+1}}{k_{t+1}}+1-(1+\phi) \delta_{t+1}\right],
$$

where $\epsilon(\sigma-1)$ is positive in the model. If an agent becomes optimistic about next period's return on capital ${ }^{4}$, the agent will sacrifice consumption today for more investment and higher future consumption, thereby lowering $c_{t}$ and raising $k_{t+1}$ and $c_{t+1}$. A higher value for $c_{t+1}$ combined with a lower value for $c_{t}$ causes the term $\left(\frac{c_{t+1}}{c_{t}}\right)^{\sigma}$ to increase. Other agents with the same optimistic viewpoints are likely to behave similarly, then the term $\left(\frac{\bar{c}_{t+1}}{\bar{c}_{t}}\right)^{\epsilon(\sigma-1)}$ also increases. Therefore, consumption externalities make the left-hand-side of (34) increase more than Guo and Lansing (2007). To validate agents' optimistic expectations as a self-fulfilling

\footnotetext{
${ }^{3}$ The upper bound of the degree of production externality for local indeterminacy is 2.4 in Wen (1998).

${ }^{4}$ Note that $\alpha\left(y_{t+1} / k_{t+1}\right)+1$ is gross return on capital, and $\alpha\left(y_{t+1} / k_{t+1}\right)+1-(1+\phi) \delta_{t+1}$ is net return on capital.
} 
equilibrium, we require the right-hand-side of (34) to increase more, i.e., as an increasing function of $k_{t+1}$, next period's net return on capital must increase more rapidly. Actually, the reason why the lower bound of production externality does not reduced greatly is that the equilibrium elasticity of output with respect to labor $\alpha_{n}$ is not changed by incorporating consumption externality in this way.

\section{The Concluding Remarks}

This paper extends straightforward the one-sector, increasing returns-to-scale, and endogenous capital depreciation model of Guo and Lansing (2007) by incorporating negative consumption externality embodying "jealousy" and "running away from the Joneses". Due to the existence of consumption externality, the necessary and sufficient conditions for local indeterminacy are changed correspondingly. Compared to Guo and Lansing (2007), the upper bounds of production externalities for local indeterminacy are reduced greatly, and the lower bounds of production externalities for local indeterminacy are also reduced, however, quantitatively very small. When the degree of consumption externality increases, the upper and lower bounds of production externalities for local indeterminacy are both reduced. In a word, consumption externality decreases the requirements on the degree of production externality for local indeterminacy in the RBC model. In the future research, we may examine the possible equivalence (or tradeoffs) between consumption externality and production externality in a standard RBC model.

\section{Appendix}

Proof of Proposition 1: It is easy to know that $\operatorname{det}(J)<1$ if and only if $-\alpha_{c} \lambda_{1}<\lambda_{4}$ and $\lambda_{4}>0$, or $-\alpha_{c} \lambda_{1}>\lambda_{4}$ and $\lambda_{4}<0$. If we can rule out the case of $-\alpha_{c} \lambda_{1}<\lambda_{4}$ and $\lambda_{4}<0$, it will be done. Since $-\alpha_{c} \lambda_{1}>\lambda_{4} \Leftrightarrow-\alpha_{c}\left[1-\frac{\alpha_{k} \delta(1+r)[\theta-\alpha(1+\phi)]}{\alpha\left(\alpha_{n}-1-r\right)}\right]>-\alpha_{c}\left[1-\frac{\alpha_{n}(1-\beta)}{\alpha_{n}-1-\gamma}\right] \Leftrightarrow \frac{\alpha_{k} \delta(1+r)[\theta-\alpha(1+\phi)]}{\alpha\left(\alpha_{n}-1-r\right)}<$ $\frac{\alpha_{n}(1-\beta)}{\alpha_{n}-1-\gamma} \Leftrightarrow(1+\gamma)[\theta-\alpha(1+\phi)]<\beta(1-\alpha) \theta \Leftrightarrow \frac{\theta}{1+\phi}<\frac{\alpha(1+\gamma)}{(1+\gamma)-\beta(1-\alpha)}$, and $\frac{\theta}{1+\phi}>1$, we have $\frac{\alpha}{1+\gamma-\beta(1-\alpha)}>1$, which implies that $(1-\beta)(1+\gamma-\alpha)<0$ contradicting the basic assumptions of the model.

Note that: (1) $\alpha_{c}<0$ (due to $\sigma<1$ ) leads to the second equivalent relationship; (2) the third equivalent relationship results from $\alpha_{n}-1-\gamma>0$, which is a necessary (but not sufficient) condition for local indeterminacy in this class of one-sector RBC models (Benhabib and Farmer (1994), Farmer and Guo (1994), Wen (1998), and Guo and Lansing (2007)). 


\section{References}

[1] Alonso-Carrera, J., and X. Raurich (2008), "Can Consumption Spillovers Be a Source of Equilibrium Indeterminacy," Journal of Economic Dynamics and Control 32, 2883-2902.

[2] Benhabib, J., and R. Farmer (1994), "Indeterminacy and Increasing Returns," Journal of Economic Theory 63, 19-14.

[3] Benhabib, J., and R. Farmer (1996), "Indeterminacy and Sector-Specific Externalities," Journal of Monetary Economics 37, 421-444.

[4] Dupor, B., and W. Liu (2003), "Jealousy and Equilibrium Overconsumption," The American Economic Review 93(1), 423-428.

[5] Farmer, R., and J. Guo (1994), "Indeterminacy with Capital Utilization and Sector-specific Externalities," Economics Letters 72, 355-360.

[6] Guo, J. (1999), "Indeterminacy and Keeping up with the Joneses," Journal of Quantitative Economics 15, 17-27.

[7] Guo, J., and S. Harrison (2001), "Indeterminacy with Capital Utilization and Sector-Specific Externalities," Economics Letters 72, 355-360.

[8] Guo, J., and K. Lansing (2007), "Maintenance Expenditures and Indeterminacy under Increasing Returns to Scale," International Journal of Eeconomic Theory 3(2), 147-158.

[9] Harrison, S. (2001), "Indeterminacy in a Model with Sector-Specific Externalities," Journal of Economic Dynamics and Control 25, 747-764.

[10] Licandro, O., and L. Puch (2000), "Capital Utilization, Maintenance Costs, and the Business Cycle," Annales D'Economie et de Statistique 58, 143-164.

[11] Liu, W., and S. Turnovsky (2005), "Consumption Externalities, Production Externalities, and Long-Run Macroeconomic Efficiency," Journal of Public Economics 89, 1097-1129.

[12] McGrattan, E., and J. Schmitz (1999), "Maintenance and Repair: Too Big to Ignore," Federal Reserve Bank of Minneapolis Quarterly Review 23(4), 2-13.

[13] Perli, R. (1998), "Indeterminacy, Home Production, and the Business Cycle: A Calibrated Analysis," Journal of Monetary Economics 41, 105-125. 
[14] Weder, M. (2000), "Consumption Externalities, Production Externalities and indeterminacy," Metroeconomica 51, 435-453.

[15] Wen, Y. (1998), "Capacity Utilization under Increasing Return to Scale," Journal of Economic Theory 81, 7-36. 

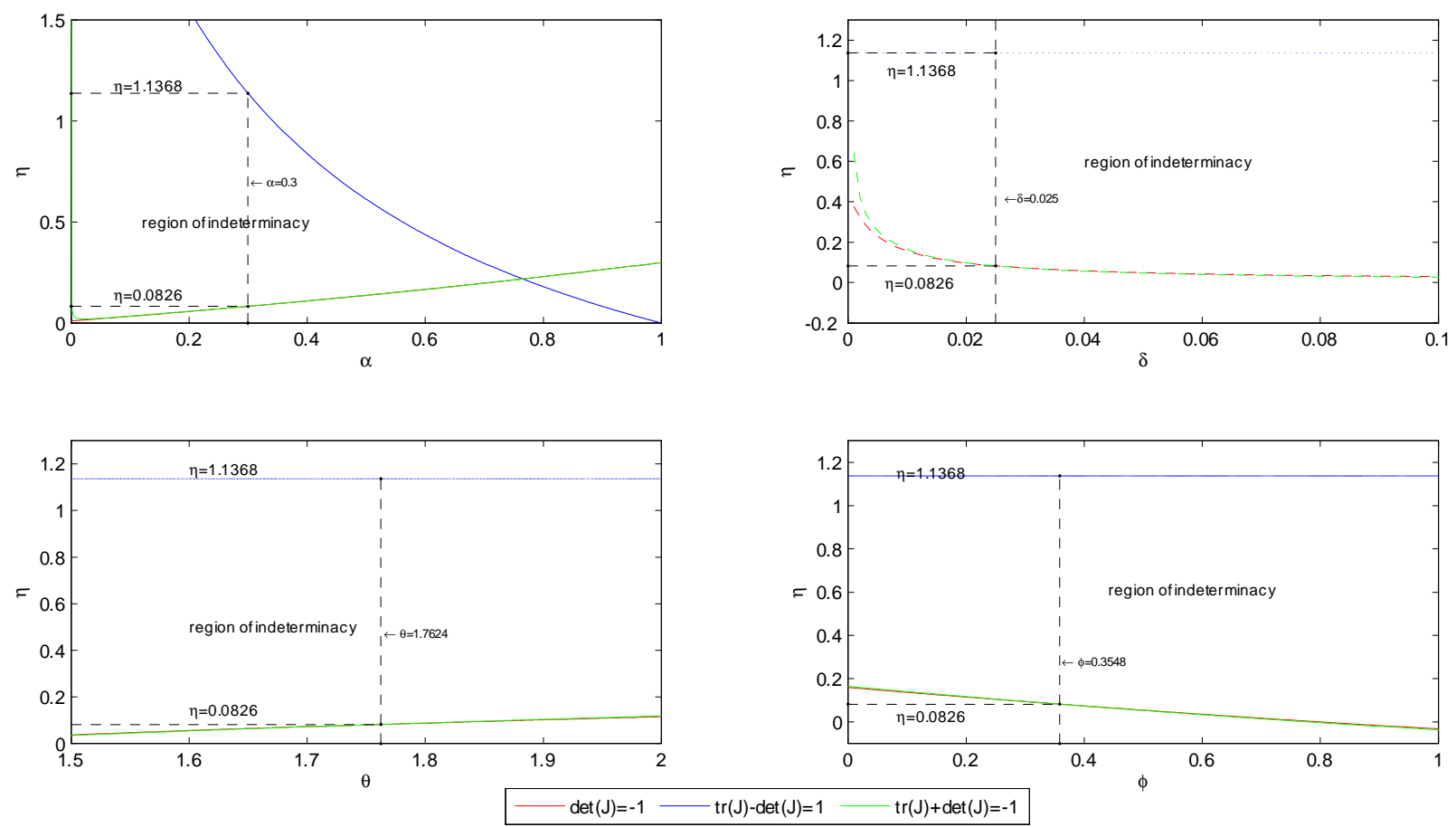

Figure 1: Regions of indeterminacy in the model ( $\eta$ is on the vertical axis). For each window, the upper line surrounding the region of indeterminacy is given by the constraint $\eta<\frac{1}{(1-\alpha)(1-\sigma)(1-\epsilon)+\alpha}-1$, the bottom lines are given by constraints $-1<\operatorname{det}(J)$, and $-[1+\operatorname{det}(J)]<\operatorname{tr}(J)$. 

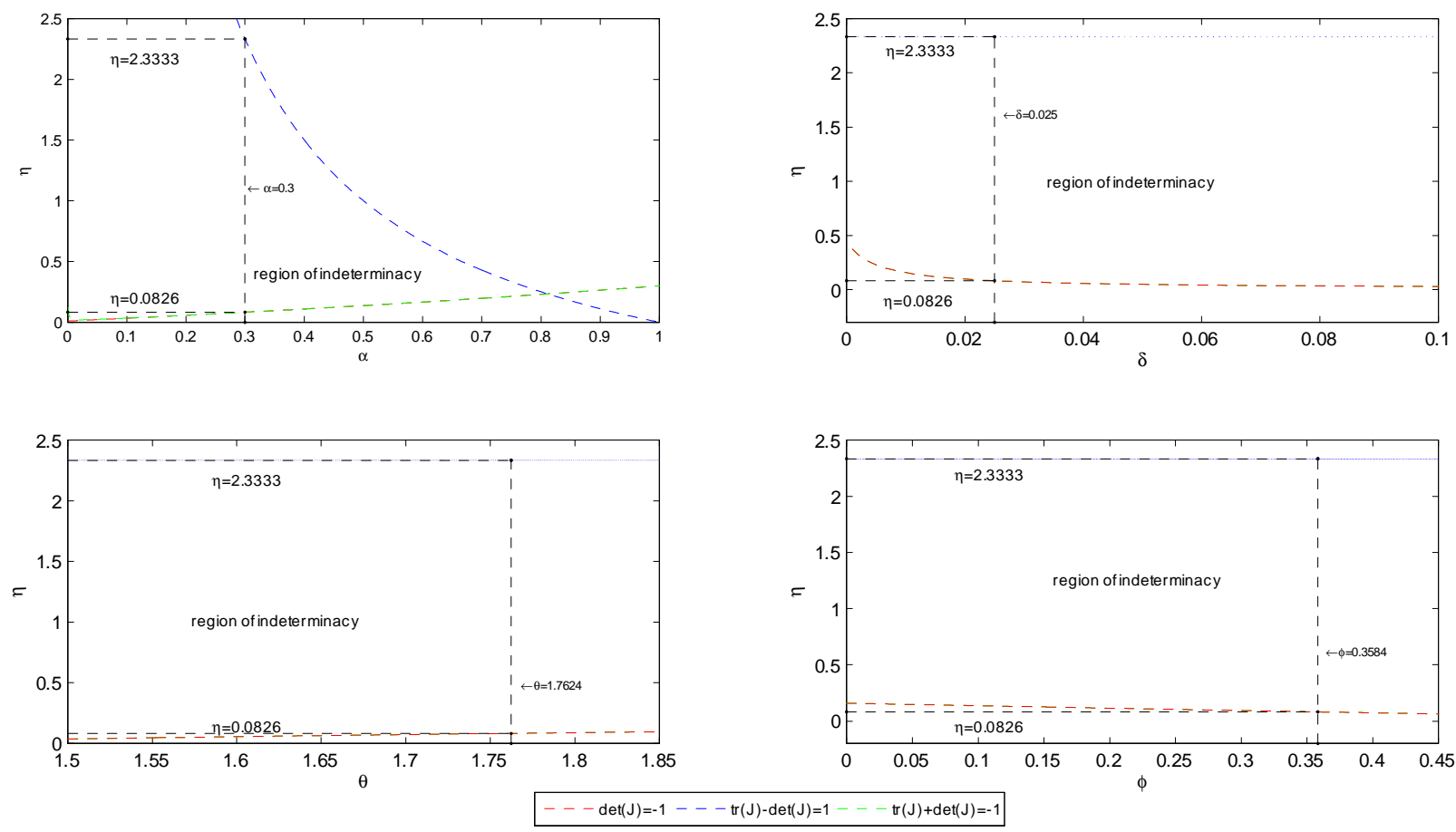

Figure 2: Regions of indeterminacy in Guo and Lansing (2007). For each window, the upper line surrounding the region of indeterminacy is given by the constraint $\eta<\frac{1}{\alpha}-1$, the bottom lines are given by constraints $-1<\operatorname{det}(J)$, and $-[1+\operatorname{det}(J)]<\operatorname{tr}(J)$. 


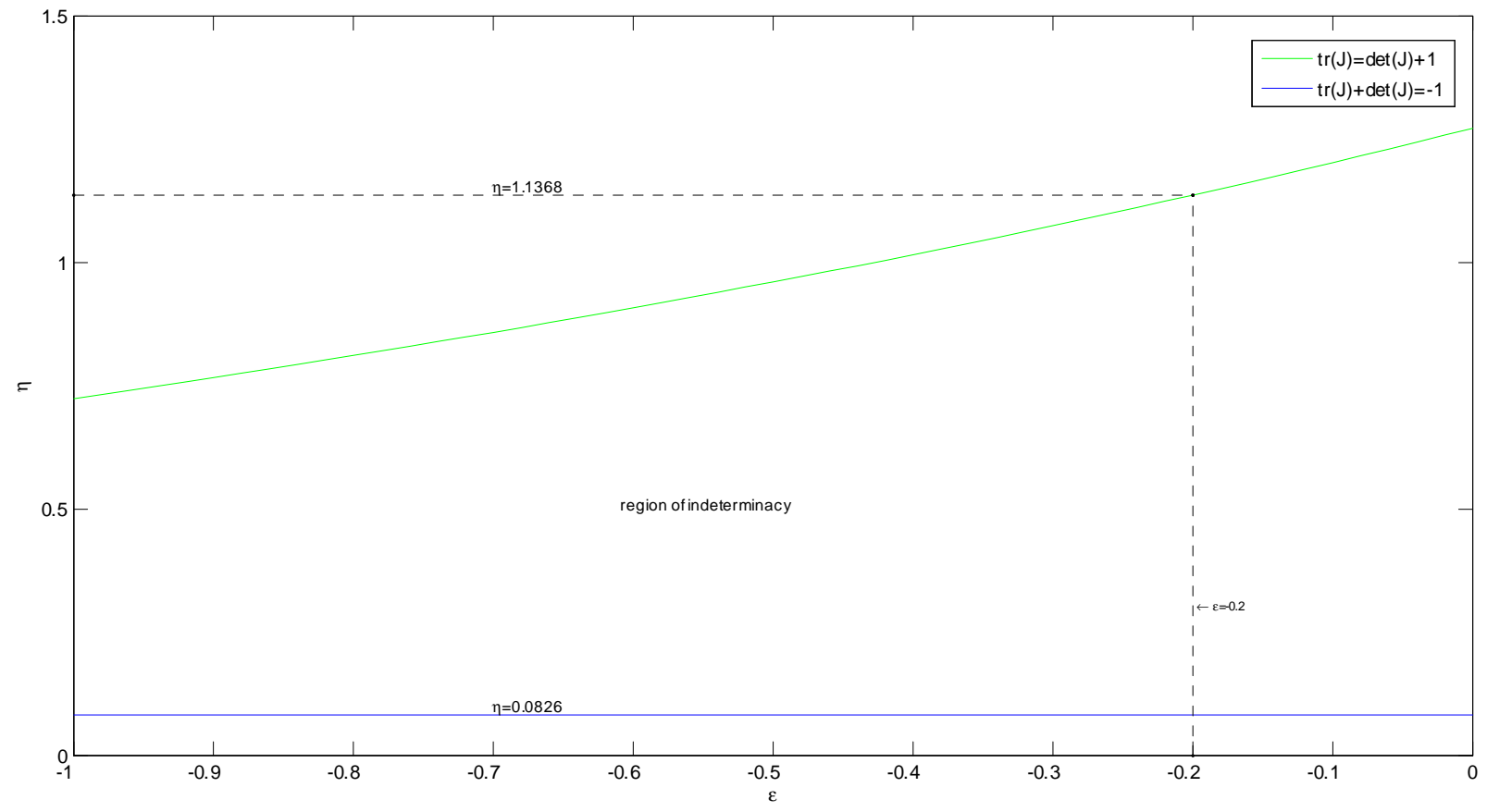

Figure 3: Regions of indeterminacy ( $\eta$ is on the vertical axis). When the degree of consumption externality $\epsilon$ increases, the requirements of production externality for local indeterminacy are reduced. 


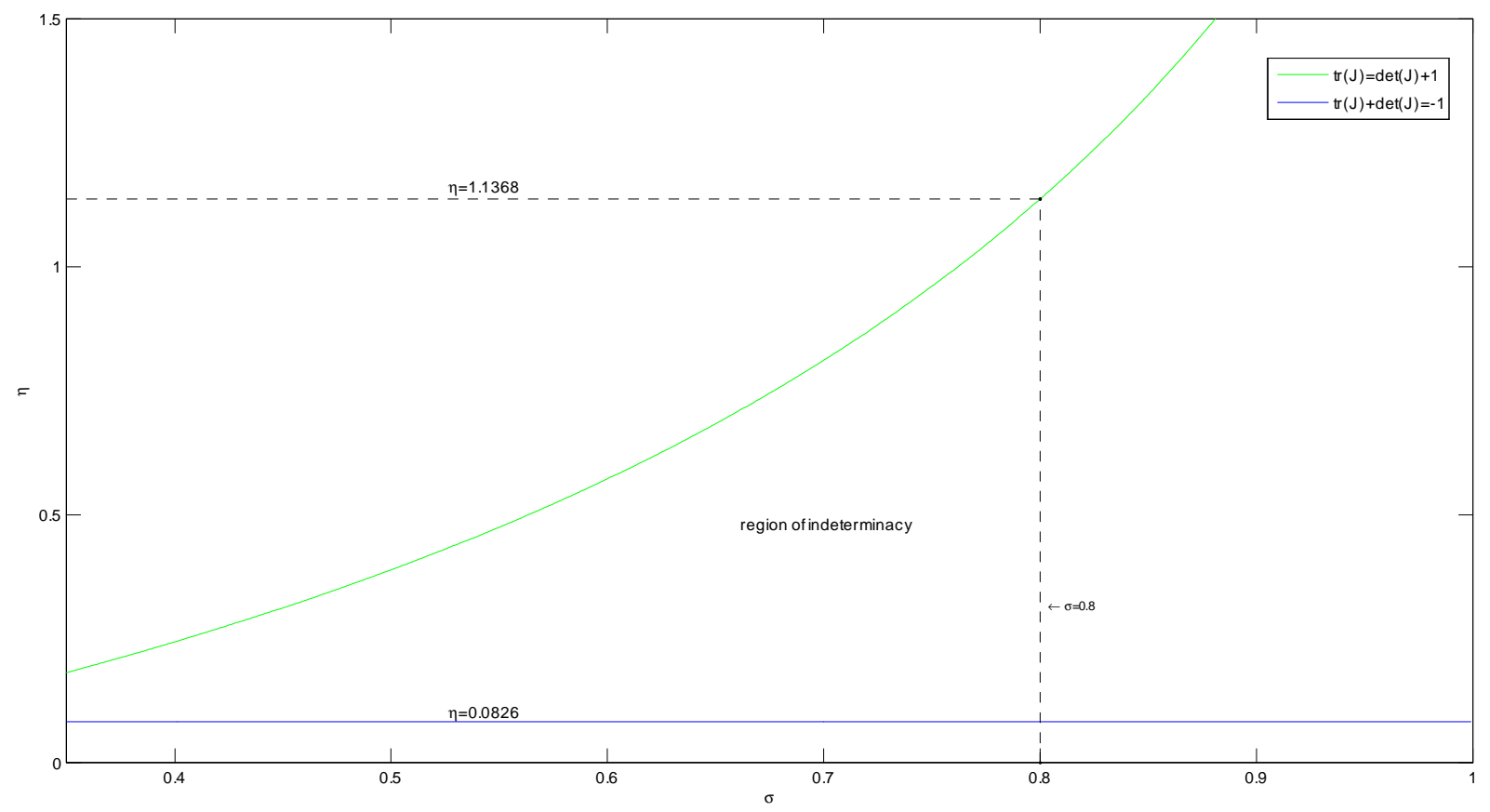

Figure 4: Regions of indeterminacy ( $\eta$ is on the vertical axis). When the relative risk aversion $\sigma$ decreases, the requirements of production externality for local indeterminacy are also reduced. 